\title{
UM ESTUDO SOBRE DIREITO FUNDAMENTAL AO ACESSO À PRESTAÇÃO JURISDICIONAL CÉLERE NO PROCESSO ELETRÔNICO
}

Luciane Mara Correa Gomes ${ }^{1}$

\section{Resumo}

A ideia de uma tutela jurisdicional tempestiva, efetiva e adequada culminou na elevação da razoável duração do processo à categoria de direito fundamental, a partir da Emenda Constitucional n. 45 e institucionalizando como ferramenta o processo eletrônico no campo judiciário. A partir da vigência da legislação processual cível, em 2015, adotando sua primazia, sem implantar políticas públicas para acessibilidade. A celeuma desta pesquisa é avaliar a sua efetividade, considerando haver 4,5 milhões de excluídos digitais no país, como também seu impacto sobre a taxa de congestionamento; amparada em metodologia qualitativa, faz a análise de dados do Conselho Nacional de Justiça.

Palavras chave: Princípio da razoável duração do processo; processo eletrônico; taxa de congestionamento; exclusão digital; Conselho Nacional de Justiça.

\section{A RESEARCH ON FUNDAMENTAL RIGHT TO ACCESS TO CELERATE JURISDICTIONAL PROVISION IN THE ELECTRONIC PROCESS}

\begin{abstract}
The idea of timely, effective and adequate judicial protection culminated in elevation of reasonable duration of the process to category of fundamental right, based on Constitutional Amendment no. 45 and institutionalizing electronic process in the judicial field as a tool. As of the civil procedural legislation, in 2015, adopting its primacy, without implementing public policies for accessibility. The stir of this research is to evaluate its effectiveness, considering that there are 4.5 million digitally excluded people in the country, as well as its impact on the congestion rate; supported by qualitative methodology, it analyzes data from National Council of Justice.
\end{abstract}

Keywords: Principle of reasonable duration of the process; electronic process; congestion rate; digital exclusion; National Council of Justice.

\section{INTRODUÇÃO}

\footnotetext{
${ }^{1}$ Mestre em Direito Público e Evolução Social pela Universidade Estácio de Sá. Bacharel em Ciências Jurídicas e Ciências Sociais pela Universidade Federal do Rio de Janeiro. Membro do Colégio de Professores da Academia Brasileira de Direito Constitucional. Associada da Associação Brasileira de Pesquisadores em Sociologia do Direito. Associada do Instituto Iberoamericano de Estudos Jurídicos. E-mail: lucianemara@uol.com.br; https://orcid.org/0000-0002-5942-2377, link do Lattes: http://lattes.cnpq.br/7142619530244859
} 
Deve-se iniciar o presente trabalho pontuando que as garantias processuais constitucionais, em especial aquelas decorrentes do acesso qualitativo à prestação jurisdicional, correspondem a réplicas de modelos alienígenas, que puderam atingir o efeito pretendido naquele Estado, e que encontram dificuldade de correlacionar a sua eficácia ante a extensão territorial do país, como também face o modelo de gestão e organização judiciária a cargo das unidades federativas, que denotam a restrição de sua repercussão no Brasil. Esta posição é necessária para vindicar que o modelo de acesso à justiça, que até os dias atuais são debatidos nas academias brasileiras, desde os anos 90 do século passado, foi objeto de estudo na década de 70, como apontado pelo Projeto Ford e, nos dias atuais, é causa de tantas digressões.

Assim, percebe-se que o atraso, diante da posição dos países que tomaram parte naquela pesquisa, causa reflexos negativos na imagem do poder judiciário brasileiro. É cabível sustentar que as técnicas aplicadas para ampliar o acesso à justiça, como apontado por Cappelletti e Garth, enfrentam resistência por parte de diversos atores sociais em virtude de exigir para sua funcionalidade promover inserções no modo de acessibilidade à prestação jurisdicional; implicando em difundir o incentivo à cultura de composição de conflitos; executar modificações para alcançar a operacionalidade dos meios de entrega da tutela judicial e acarear os problemas advindos do déficit de recursos humanos existente no campo judiciário, todos contribuindo de alguma maneira para o problema central da demora na tramitação de processos.

O enfrentamento das múltiplas possibilidades que causam o retardo na efetividade da prestação jurisdicional em terras brasileiras deve ser feito com a finalidade de avaliar se os resultados alcançados pelo Poder Judiciário e que encerra o relatório anual do Conselho Nacional de Justiça apontam a operacionalidade dos processos de gestão judiciária. É plausível argumentar que a busca por uma decisão judicial eficiente deve estar amparada na eliminação de barreiras que causem o prolongamento dos procedimentos que são necessários à prestação jurisdicional. Neste viés, a adoção do processo eletrônico, como ferramenta de otimização de protocolos de entrega do serviço público judicial, esbarra em problemas de ordem sistêmica, como também naqueles de natureza humana.

Quanto à problemática do sistema, cumpre salientar que há três pontos essenciais a construção de um sistema de processo eletrônico eficiente, onde o primeiro diz respeito à ausência de uniformização, por parte dos tribunais, de programas idênticos. Cada esfera judiciária adotou um modelo e a pluralidade de sistemas operacionais implica em absorver habilidades diversas para o seu manuseio. Esta variável contribui também para o aparecimento 
de problemas técnicos que exige dos usuários um conhecimento mais amplo de tecnologia da informação, enquanto que a unificação, por seu turno, estaria atendendo aos requisitos de universalidade de acesso, tornando mais concentrado as disfunções do sistema.

O segundo ponto guarda pertinência com o sistema de telecomunicações e tráfego de dados, considerando ainda a extensão territorial do país, os acidentes geográficos, como ainda aquelas áreas que são afetadas por condições climáticas, nestes locais a transmissão de dados torna-se difícil; em toda área, há exigência de uma tecnologia que ainda não alcançada no Brasil, pois causa interferência na disponibilidade do sistema do processo eletrônico, em especial quando milhares de usuários estão no acesso, o que acarreta queda no seu funcionamento, gerando indisponibilidade e dilação de prazos processuais, retardando por defeitos técnicos a sua regular utilização.

O terceiro ponto tem como foco os seus usuários, o processo eletrônico não deve ter o condão de limitar o seu acesso por quem almeja uma prestação jurisdicional e não tenha recursos de conhecimento ou de falta de equipamento para perquirir um provimento jurisdicional. Desde a utilização, passando pela consulta ou até mesmo de ter a viabilidade de acessar um processo que esteja tramitando de modo virtual, o indivíduo deve ter assegurado pelo Estado este acesso. Adotando esta linha de observação, como um conceito amplo de acesso à justiça, deve, ao impor a tramitação preferencial pelo processo virtual, tornar viável o seu alcance aos quase cinco milhões de brasileiros que são excluídos digitalmente. Desconsiderar este acesso, onde há pontos nítidos de exclusão social, implica para o próprio Estado fomentar a ruptura do exercício do direito fundamental de inafastabilidade da prestação jurisdicional de modo material e formalmente inapropriado.

Desta forma, o processo eletrônico evidencia a desigualdade entre as partes, em especial, no que tange às barreiras econômicas e culturais, contudo é um método que contempla hipótese de garantia de um processo justo, se partir da premissa que o processo virtual tornará o Poder Judiciário mais célere, já que os tribunais estão condicionados a fornecer alternativas àquela parcela da população que não tem a capacitação o seu manejo; assegurando, dentro da codificação processual civil, possibilidades de acesso tecnológico ao processo eletrônico. Se pensado sob este prisma, os $12,4 \%$ da população brasileira que são tipificados como analfabetos digitais, dados oriundos do Instituto Brasileiro de Geografia e Estatística, que foram levantados em 2005, não haverá o cerceamento à prestação judicial. Cabendo doravante analisar se o 
processo eletrônico é ferramenta hábil para reduzir os indicadores de taxa de congestionamento, vindo a propiciar a eficácia da garantia fundamental.

Diante da abordagem apresentada, a pesquisa se ocupa em avaliar se o processo eletrônico possibilita a redução da taxa de congestionamento dos tribunais, mesmo com a afetação de parte da população, que é excluída digitalmente, explicitando como se operacionaliza o acesso à prestação jurisdicional por meio virtual, a partir dos dados estatísticos do ano de 2018, apresentados pelo Conselho Nacional de Justiça, no ano de 2019, no projeto Justiça em Números. A pesquisa é estruturada em metodologia qualitativa, com revisão bibliográfica para embasamento teórico diante da análise dos resultados apresentados pelo Conselho Nacional de Justiça.

\section{A IMPLEMENTAÇÃO DO ACESSO À PRESTAÇÃO JURISDICIONAL ELETRÔNICA E O ENFRENTAMENTO DAS DESIGUALDADES GERADAS PELAS TECNOLOGIAS DIGITAIS}

A codificação processual civil uniformizou que a tramitação dos processos será feita, preferencialmente, por meio virtual, implicando no cerceamento do acesso à justiça por uma parcela considerável da população que possui o potencial para ajuizar uma demanda pelo rito dos juizados especiais, sejam eles cíveis, fazendários ou federais, onde é facultada a atuação sem advogado, ou ainda, por parte de advogados que não tenham habilidades com tecnologias ou portadores de necessidades especiais que carecem de uma estrutura específica à sua limitação. Como equalizar a concessão de meios para restabelecer o equilíbrio desta parcela de indivíduos num ambiente de práticas desmaterializadas que é o ambiente virtual dos processos judiciais.

Se por um lado a sua implantação tem como objetivo a redução de custo operacional do acerbo físico, acolhendo a necessidade de programação de espaço físico para as serventias e arquivos, o processo eletrônico vem otimizar a deficiência de servidores, já que a digitalização e indexação de petições passou a ser da parte do advogado ou da parte. No outro polo, os envolvidos no litígio são compelidos a obter equipamentos, com a finalidade de estar inseridos no ambiente virtual dos processos e que não é de fácil acesso daquela parcela da população anteriormente referida, seja por questões financeiras, seja por questões culturais. Assim, é possível vislumbrar que uma gama de pessoas despreparadas para a atuação no ambiente 
eletrônico estará compulsoriamente requisitada a agir, sem as habilidades necessárias, por conta de uma imposição legal que fomente a desigualdade de armas.

É oportuno lembrar que a legislação processual garante a todos a prática de atos processuais por meio eletrônico, nesta universalidade estão incluídos aqueles que não possuem conhecimento tecnológico, como idosos com mais de 60 anos, indivíduos que não tenham habilidades com as tecnologias digitais, os portadores de deficiência que, com o processo físico realizavam suas atividades de acordo com suas capacidades, com equipamentos adequados. Cabe ressaltar, pautado no posicionamento de Wambier (2015), que esta medida os alijou tanto do exercício da advocacia, quanto do acesso ao Judiciário, violando o princípio da inafastabilidade da prestação jurisdicional. Por outro lado, Humberto Dalla Bernadina de Pinho (2015) assevera que estas barreiras de acesso serão superadas pelos jurisdicionados, já que a vantagem econômica é muito maior para a sociedade, face à simplificação da tramitação, sem deixar de observar a necessidade de se investir em educação digital, como meio de reduzir a desigualdade e como contribuição para o acesso de todos a uma ordem jurídica justa.

Importante colocação é feita por Leonardo Greco (2015, p.315) a respeito da implantação do processo eletrônico, especialmente quanto ao patrocínio pela Defensoria Pública do Estado do Rio de Janeiro, que é a titular de mais da metade dos processos existentes na unidade federativa. $\mathrm{O}$ autor pontua que a falta de equipamentos suficientes para a prática do ato processual por meio eletrônico, também se tornaria um impasse na sua realização e esta preocupação também é compartilhada por Casio Scarpinella Bueno (2015). A posição é complementada por José Miguel Garcia Medina (2015) ao esclarecer que o Estado, ao mitigar a acessibilidade digital, dá azo a violação dos direitos das pessoas portadoras de deficiência, dando ênfase à violação de convenção internacional ratificada pelo Brasil, destinada a proteção da dignidade enquanto pessoa humana e que, em tese, tem o dever de assegurar o acesso a novos sistemas e tecnologias da informação e comunicação.

O Conselho Nacional de Justiça, ao regular o processo eletrônico, através da Recomendação n. 27, de 16 de dezembro de 2009, não dá efetividade ao padrão de acessibilidade da "remoção de quaisquer barreiras que pudessem impedir elou dificultar o acesso das pessoas com deficiência" nem exige o cumprimento pelos tribunais brasileiros. Ainda sobre o aspecto da acessibilidade ao processo eletrônico, o Conselho Nacional de Justiça, através da Resolução n 185, determina aos órgãos do Poder Judiciário a instalação de equipamentos e auxílio técnico presencial às pessoas com deficiência e idosos. Muito embora, o que foi referendado pela 
legislação processual vigente não é suficiente por não conceder tecnologias adequadas aos portadores de deficiência, muito menos acatado nas unidades federativas do país. A solução adequada se operou com a possibilidade dos Tribunais brasileiros se estruturarem no sentido de possuir dependências que acomodem o acesso ao peticionamento, almejando facilitar a instalação ou mesmo optando por celebrar convênios com outros órgãos, proporcionando o Poder Judiciário manter a estrutura em suas dependências de acesso à prática de atos processuais por meio eletrônico, acomodadas em instalações adequadas ao desempenho da distribuição dos encargos na comunicação e prática de atos, que é um dos objetivos da migração de processo físico para virtual, visando conferir agilidade às fases processuais.

Cabe ainda trazer a posição de Pinho (2015) no diz respeito às metas do processo eletrônico que é a possibilidade de redução nas custas processuais e, por conseguinte, a resolução do conflito será célere, que poderá ser identificado a partir da apresentação dos resultados estatísticos do Conselho Nacional de Justiça. Antonio José Carvalho da Silva Filho salienta que a redistribuição dos trabalhos burocráticos entre os participantes do processo como um dos principais objetivos que é a celeridade, sendo consequência do descumprimento do dever estatal, posição endossada por Cunha, Bochenek e Cambi (2015). Considerando que, no âmbito do processo eletrônico, busca-se distribuir as responsabilidades no impulso da demanda judicial e se, o Estado impõe a todos esta tarefa, o ponto ideal seria que a todos fossem conferidos pelo campo judiciário os meios para atingir a meta proposta. Ao impor condições igualitárias a todos sem fornecer as condições necessárias para minimizar as dificuldades impostas pelas condições culturais, sociais, estruturais, o Estado falha na concessão do acesso. Neste caso, o ente estatal deveria ser o primeiro a se adaptar a tendência de desmaterialização e virtualização do processo, vez que são ações destinadas a simplificar o procedimento e assegurando a tutela dos direitos a todos sem qualquer distinção (THEODORO JUNIOR, OLIVEIRA, REZENDE, 2015, p. 157).

O campo das tecnologias da informação sofre constantes modificações e avanços e que serão necessários para a manutenção do processo judicial eletrônico. Sendo previsto pelo Conselho Nacional de Justiça ao regulamentar que as alterações dos sistemas processuais não serão barreiras estruturais, cabendo aos tribunais a realização das correspondentes alterações. Neste quadro, Humberto Theodoro Junior (2015) pondera que o Conselho Nacional de Justiça ao disciplinar a incorporação progressiva dos novos avanços tecnológicos, com a finalidade de não se tornar obsoleto, deveriam ser modificados quando da necessidade de sua modernização, o que aponta para a falta de acesso às novas tecnologias, como replicador de desigualdades, o que não 
é aceitável, em especial se for considerada que a escolha pela tramitação processual pela via desmaterializada teve como fundamento a garantia de uma prestação jurisdicional mais célere, mais econômica e menos burocratizada.

O debate traçado em torno da eficiência do processo eletrônico no combater à lentidão processual deve estar focado na otimização no trâmite dos processos atendendo as garantias fundamentais da Constituição para o processo efetivo, célere e econômico. Contudo, é oportuno mencionar que não basta apenas haver o processo eletrônico que o indivíduo esteja municiado das habilidades para o exercício da cidadania, as condições de igualdade entre as partes devem estar equilibradas para que a entrega de uma prestação jurisdicional de modo que o acesso à Justiça seja concreta, livre de barreiras que limitem a atuação em juízo seja como parte, seja como operador do Direito. A prática do processo eletrônico vai confrontar a celeuma da escassez de recursos humanos para o âmbito dos cartórios, apresentando indicativos para a problemática do acúmulo de processos físicos, podendo permanecer afetada a eficiência em processos virtuais pelas mesmas razões.

Noutro giro, não houve medida ou soluções de ordem técnica para a barreira cultural que existe, principalmente para as camadas que ainda não tem acesso à tecnologia da informação, o que torna o processo eletrônico, regulado pela Lei Federal n. 11.419, vigente desde 2006, letra morta em relação à garantia constitucional de acesso à justiça. Código de Processo Civil transmutou o acesso pela via dos processos eletrônicos e passou a tomar parte do funcionamento dos Tribunais de Justiça, gerando preocupações concernentes quanto à sua estrutura, já que tanto os servidores passarão a promover, como também os jurisdicionados, a conexão com a realidade do processo eletrônico. Ademais, deve-se levar em consideração que, na ausência da estrutura de informática, haverá de ser suprida a deficiência com acessibilidade por métodos alternativos ao processo eletrônico, situação suportada pelas unidades do Poder Judiciário, onde houver esta falha na prestação do serviço, celeuma oriunda da questão de extensão ao analfabetismo digital, que é uma das formas de exclusão do século XXI. Desta forma, é necessário pensar que a estruturação deste ambiente é um mecanismo de efetivação de políticas públicas de acessabilidade digital no campo do Poder Judiciário que aponta não só para um ambiente mais célere, como também mais sustentável.

Reporta-se aqui ao necessário meio de atribuir em condição de igualdade material e formal o pleno acesso à Justiça, quando se trata de garantir ao indivíduo ,que é excluído digitalmente, a possibilidade de ter o acesso eletrônico. Percebe-se aqui o paradoxo da sociedade 
informatizada está envolvendo no problema da falta de servidores para dar movimentação aos processos constantes nos acervos cartorários, a desigualdade social. A efetivação do acesso ao processo eletrônico comporta pensar o qual o objetivo da norma, para compreender a solução menos lesiva ao jurisdicionado, sem deixar de observar que a paridade de armas deverá ser preservada, sem causar prejuízo à duração razoável do processo. Neste circuito, deve-se agregar os fatores da falta de conhecimento de tecnologia da informação, a ausência de recursos materiais para a propositura de ações judiciais pelo processo eletrônico e a falta de planejamento estrutural do campo judiciário, em especial no seu quadro de recursos humanos, com vias a cumprir as políticas públicas judiciárias de eficácia do processo eletrônico.

\section{A EFICÁCIA dO PROCESSO ELETRÔNICO PELA PERSPECTIVA DO CONSELHO NACIONAL DE JUSTIÇA}

Para avaliar a condição do processo como ferramenta para reduzir o tempo de tramitação de um litígio, precisa-se considerar o prazo médio de uma demanda, a fim de constatar se o intervalo entre a data da sua propositura até a sua baixa definitiva foi um lapso temporal capaz de representar uma prestação jurisdicional tempestiva, célere e adequada. A partir desta perspectiva, o trabalho passa a avaliar os dados estatísticos do Conselho Nacional de Justiça, para o ano de 2018, divulgados no Projeto Justiça em Números 2019. O recorte adotado foi, a partir dos dados totalizados para a estrutura do Poder Judiciário, conceder o que foi produzido pelo primeiro grau de jurisdição e pelos juizados especiais, limitando as esferas da justiça estadual, trabalhista e federal, escolha adotada por serem as unidades que mais são requisitadas pelo homem mediano.

Para que a pesquisa possa avaliar a contribuição do processo eletrônico em face da movimentação processual, é necessário estabelecer o recorte de como está configurada a estrutura do campo judiciário, para confrontar o volume de trabalho diante da força de trabalho existente. Neste parâmetro, o Poder Judiciário brasileiro tem um total de 14.877 unidades judiciárias, que são divididas em 9.627 unidades na justiça estadual, deste montante, 8.348 são varas e 1.279 juizados. Esta estrutura, no âmbito da justiça do trabalho, é composta por 1.587 varas enquanto que na justiça federal há 772 varas e 215 juizados especiais federais em toda extensão territorial. Importa apresentar ainda o quadro de recursos humanos que está distribuído dentre as unidades judiciárias e que é responsável pela circulação da carga de trabalho, neste 
viés, é possível contrastar que quanto maior for a estrutura da justiça especializada, maior será a carga de trabalho e maior o número de recursos humanos.

Inicializa-se a verificação com os dados apresentados para a justiça estadual, onde há 12.472 magistrados e 174.487 servidores, sendo 148.303 são efetivos; 9.745 cedidos ou requisitados e 16.439 sem vínculo efetivo e 115.897 auxiliares. Este quadro de força de trabalho movimenta um acervo de 17.136.250 casos novos, no ano de 2018, na esfera não criminal. Neste período foram julgados 20.148.591 casos e baixados 19.373 .744 feitos, resultando num acervo de 44.454.514 processos. A percepção de razoável duração do processo deve ainda conter a avaliação do tempo de tramitação de uma lide, para que se possa ponderar a eficácia do processo eletrônico. A princípio, o tempo gasto para a prolatação de uma sentença, desde a sua distribuição, é de, em média, 1 ano e 11 meses na fase de conhecimento do primeiro grau de jurisdição, enquanto que na fase de execução, 5 anos e 8 meses. $\mathrm{O}$ processo pendente, como aquele que não teve sua baixa definitiva no ano anterior e no corrente, demanda em fase de conhecimento 3 anos e 8 meses e na fase de execução, 6 anos e 5 meses. Nesta mesma proporção, quando a leitura dos dados estatísticos é dos processos em sede de juizados especiais há redução de tempo para a prolatação da sentença, pois na fase de conhecimento passa para 10 meses e na de execução reduz para um ano. Quanto ao tempo do processo pendente, este prazo reduz para um ano e 10 meses em fase de conhecimento e na fase de execução é de 2 anos.

Considerando o volume de processos, o Poder Judiciário recebeu, no ano de 2018, 19.579.314 casos novos; sendo no primeiro grau, 11.555.694 e 4.834.977, nos juizados especiais cíveis. Avaliando que em fase de conhecimento, apenas considerando os feitos de natureza não criminal foi distribuídos 5.553 .623 em fase de conhecimento e 4.444 .914 no rito de execução. Em se tratando de juizados especiais cíveis, estes números se apresentam da seguinte forma: no conhecimento, 3.514.142 e no de execução reduz para 1.031.689. Após considerarmos o volume de entrada, cabe apurar o quantitativo de feitos sentenciados para melhor percepção de que fase do procedimento há maior concentração de processos. Durante o ano de 2018, foram proferidas 22.954.470 sentenças onde 8.066.485 foram produzidas em fase de conhecimento e 4.244.259 em fase de execução. No âmbito dos juizados especiais cíveis, no mesmo período, foram proferidas 4.250.744 sentenças na fase de conhecimento e 1.082.134 na fase de execução.

No que se refere à observação dos processos baixados no mesmo ano, houve 22.269.043 casos com a baixa definitiva, representando a consolidação da prestação jurisdicional Deste acervo, 13.412.061 processos em primeiro grau de jurisdição, sendo na fase de conhecimento 
7.026.424 e na fase de execução 4.606.953 apenas os feitos de natureza não criminal. Esta perspectiva, no âmbito dos juizados especiais passa para 4.077.715 na fase de conhecimento e 1.055.365 na execução. Por este ponto, percebe-se que houve mais processos baixados do que casos novos, o que pode ser atribuído a capacidade da força de trabalho poder encerrar mais processos do que a estrutura teria recebido no igual período.

Não obstante o desforço ainda existe um acervo processual de 62.988 .042 processos pendentes, cabendo ao primeiro grau de jurisdição 54.524 .693 feitos, considerando 15.713 .242 na fase de conhecimento e outros 32.287.492 na de execução. Quando avalia-se o volume de dados advindos dos juizados especiais cíveis, tem-se que o acervo passa para 5.560.770, onde 3.724.795 processos estão represados na fase de conhecimento e 1.189.743 na fase de execução.

Se o acervo avaliado é movimentado só no primeiro grau de jurisdição por 9.472 magistrados com o suporte de 112.647 servidores e nos juizados este número reduz para 3.039 magistrados e 21.115 servidores, a taxa de congestionamento que está concentrada na primeira instância em $80,3 \%$ onde $70,8 \%$ do volume é na fase de conhecimento e 87,5\% na fase de execução. A primeira perspectiva é de que a maior tempo se consome na fase de efetivação da prestação jurisdicional, o prejuízo está no cumprimento da sentença involuntário. Este posicionamento não é o mesmo quando verificada a taxa de congestionamento dos juizados especiais que é de 49,8\% sendo na fase de conhecimento 48,9\% e na de execução, $53,2 \%$, uma vez que o volume é três vezes maior até a prolatação da sentença em comparação do acervo em vias executórias. É importante frisar que os indicadores de gestão apontam que $83 \%$ dos processos em tramitação na justiça estadual são por meio eletrônico, o que afasta a hipótese de atribuir a demora na entrega da prestação jurisdicional ao manejo de volume físico que contribui para o tempo morto em que o processo espera o impulso processual.

É necessário voltar o objetivo desta pesquisa, a partir dos dados fornecidos no âmbito da Justiça do Trabalho, para averiguar pela perspectiva da concentração pela sua especialização. Tomando como ponto de partida o tempo para sentença em primeiro grau de jurisdição na fase de conhecimento é de 9 meses e na fase de execução de 2 ano e 9 meses. Em contrapartida, quando se avalia o tempo de processo pendente, esta media para, em fase de conhecimento para um ano e cinco meses e na fase de execução para quatro anos e um mês. Diante destas considerações a respeito do tempo médio de duração da demanda, cabe ponderar se o tempo é regular ou prolongado se comparado com o volume de demandas que tramita nesta justiça especializada. 
Doravante, ocupa-se de investigar os dados do setor de distribuição no ano de 2018 e constatou-se que foram distribuídos 3.460.875 processos, é necessário pontuar que $98 \%$ deste acervo de casos novos foi apresentado por meio eletrônico. Deste volume, dirigiu-se ao primeiro grau de jurisdição o total de 2.531.200 feitos, sendo deste montante 1.732.367 na fase de conhecimento e 798.893 na fase de execução. No que se destina a prolatação de sentenças, com o intuito de verificar se entre a distribuição e a prolatação da sentença o prazo satisfaz a garantia constitucional, neste período, foram prolatadas 4.367.437 sentenças, onde 3.286.101 no primeiro grau de jurisdição, distribuídos em 2.489.421 na fase de conhecimento e 796.680, na execução. A atuação da força de trabalho no que concerne à liquidação do acervo distribuído é satisfatória pois além de suprimir o quantitativo distribuído no ano de 2018, pode reduzir aqueles pendentes dos anos anteriores, com exceção dos processos distribuídos em execução, que tiveram um residual de pouco mais de $0,3 \%$ comparado com a distribuição e os dados de processos sentenciados.

Cabe apresentar ainda, na seara dos processos que estão a cargo da Justiça do Trabalho que o quantitativo de processos baixados no ano de 2018 foi de 4.354.226 feitos, onde 3.517.649 ocorreram no primeiro grau de jurisdição, com 2.632.563 na fase de conhecimento e 885.086 na de execução. Isto implica afirmar que além de ter o acervo de distribuição em primeira instância com sentença, a Justiça do Trabalho deve quase a totalidade deste volume com baixa definitiva.

Cumpre ainda, para fins de verificação da efetividade do processo eletrônico como método para materializar a duração razoável do processo, apresentar os dados pertinentes ao período analisado, de processos pendentes. Este quantitativo, na seara da justiça trabalhista é de 4.861.352 feitos, com 4.024.373 no primeiro grau de jurisdição, distribuídos na fase de conhecimento 1.609 .412 e 2.414.961 na fase de execução. Estes dados apresentam as mesmas características daqueles advindos da justiça estadual, que direcionam a celeuma da demora na entrega da prestação jurisdicional na satisfatividade da execução. Isto pode ser constatado a partir da sua produtividade, pois sua força de trabalho é composta por 3.55 magistrados e 31.106 servidores, sendo vinculados ao primeiro grau de jurisdição 3.043 juízes e 24.055 servidores, uma vez que a taca de congestionamento é de $53,4 \%$, onde $37,9 \%$ deles na fase de conhecimento e $73,2 \%$ na fase de execução.

No que se refere à justiça federal, o cenário é diferenciado pela incidência do fato de haver, ao menos num dos polos da demanda, o poder público federal, o que pode trazer algum diferencial face às prerrogativas da administração pública em juízo, que não integram as 
hipóteses desta avaliação, contudo possuem significativa expressão. Quanto ao tempo de sentença, os feitos que tramitam na fase de conhecimento do primeiro grau de jurisdição demandam 1 ano e 10 meses, enquanto que na fase de execução este tempo aumenta para 7 anos e 4 meses. Por outro lado, na esfera dos juizados especiais este intervalo reduz para 1 ano, na fase de conhecimento e 2 meses em execução.

Durante o ano de 2018, foram distribuídos 4.203.804 casos novos, onde 1.173 .423 são dirigidos ao primeiro grau de jurisdição cabendo ao conhecimento 481.671 e na execução, 597.960. Neste mesmo período foram distribuídos 1.615 .788 para os juizados especiais, o volume contrasta com a primeira instância por comportar o rito processual ações de natureza previdenciária. Houve a contabilização neste intervalo de 4.080 .423 sentenças, sendo 841.726 nos feitos em primeiro grau, onde 387.087 na fase de conhecimento e 400.880 na de execução. Em contrapartida, no âmbito dos juizados especiais, foram 2.070.222 sentenças, sendo 2.068.985 na fase de conhecimento e as demais, nos feitos de natureza criminal.

O volume de processos baixados na justiça federal corresponde a 4.406 .039 feitos, onde 1.052.811 são originários da primeira instância, sendo 467.858 na fase de conhecimento e 489.299 na fase de execução. Este levantamento quando dirigido aos processos dos juizados especiais passa a ser de 2.062.208, na fase de conhecimento, num acervo de 2.265.343. Percebese que o quantitativo de processos baixados é superior ao de casos novos, principalmente em sede de juizados especiais federais.

$\mathrm{O}$ acervo de processos pendentes no âmbito da justiça federal é de 10.085.836, sendo deste monte 6.242.613 existentes na primeira instância, com 924.718 em trâmite na fase de conhecimento e na fase de execução outros 5.139.413. O elevado número corresponde às milhares de execuções fiscais distribuídas pela Fazenda Nacional com o fito de recuperar os créditos tributários não recebidos pela cobrança administrativa, causando um fluxo elevado de feitos tramitando nas varas de execuções fiscais, atingindo a perspectiva de satisfatividade da tutela judicial em virtude do volume de processos em tramitação. Enquanto que nos juizados especiais cíveis o acervo é de 1.762.186 que não atingiram a condição de remessa a baixa definitiva.

Importante destaque deve ser feito no que tange à força de trabalho da justiça federal, o número de magistrados é correspondente a $3 / 4$ dos lotados em juizados especiais, ou seja, o primeiro grau de jurisdição tem no seu efetivo pessoal 1.232 magistrados e 15.438 servidores para 957 magistrados e 9.105 servidores nos juizados. Este contraste aponta para a importância 
de um quadro de recursos humanos satisfatório para o desenvolvimento das rotinas cartorárias. Um ponto importante é o elevado número de casos novos direcionados aos juizados especiais, com um elevado número de sentenças prolatadas e com um reduzido acervo de processos pendentes.

É necessário apontar que o acervo de processos é de $82 \%$ feitos tramitando por meio virtual, indicando não só uma conexão entre o quadro de recursos humanos e a tramitação dos processos de modo digital, onde há um elevado número de processos distribuídos, mas também com a carga de trabalho desempenhada com valores consideráveis, visto que a taxa de congestionamento na justiça federal é de $85,6 \%$, sendo $65,9 \%$ na fase de conhecimento e $91,2 \%$ nas execuções. Enquanto que nos juizados especiais este índice é de 44,4\%, onde 46,1\% está na fase de conhecimento e apenas $17,8 \%$ na fase de execução.

Numa leitura ampla, apenas $16,2 \%$ do total geral de processos novos ingressaram fisicamente no ano de 2019 em toda a estrutura judiciária brasileira. É possível assinalar que a primeira instância da Justiça do Trabalho possui 99,9\% dos casos novos eletrônicos, contrastada com a taxa de congestionamento de 52,8\%, é possível sustentar que não se trata apenas de manter os processos por meio virtual, cabe construir uma estrutura capaz de apresentar resposta a este volume, já que a razoável duração do processo contém variáveis de infraestrutura e de mão de obra.

\section{CONCLUSÃO}

A falta de estrutura para apresentar soluções ao acúmulo de processos físicos, assim como as dificuldades de ordem técnica para extinguir a barreira cultural que existem, principalmente para as camadas que ainda não tem acesso à tecnologia da informação, são os principais pontos para que o processo eletrônico não se torne um instrumento de fomento à desigualdade. O acesso aos processos eletrônicos importa numa realidade trazida ao pleno funcionamento dos Tribunais de Justiça, traz preocupações concernentes quanto à sua estrutura, já que sua adoção é uma das ferramentas do Poder Judiciário para conferir eficácia ao direito fundamental da razoável duração do processo. É possível considerar que há reflexos sobre a adaptação à nova realidade informatizada e com inspirações de um processo mais dinâmico, menos materializado e condizente com a Constituição da República. 
A preocupação do Conselho Nacional de Justiça, desde a sua criação, é obter meios de desenvolvimento para os métodos de resolução da crise da morosidade instalada do Poder Judiciário. No entanto, neste singular ponto, não houve a percepção de que uma grande parcela da população não está tecnicamente habilitada a manusear os sistemas do processo eletrônico, seja pela ausência de conhecimento, seja pela restrição que o sistema oferece, através da ampliação de matrizes pelas quais se possam ofertar uma prestação jurisdicional mais célere é o que a doutrina tem inclinado a suscitar, sempre observando que a desigualdade existente se faz tanto por aspectos culturais, quanto por aspectos econômicos.

A análise dos indicativos de tratamento desigual das partes é somente uma das hipóteses na utilização dos sistemas de prática de atos processuais por meio eletrônico na estrutura judiciária. A avaliação do princípio da razoável duração do processo num ambiente digital traz à luz que a problemática do quadro de pessoal pertencente ao Poder Judiciário representa significativamente para a elevada taxa de congestionamento. Neste perfil, estão inseridos juízes, desembargadores, ministros, servidores do quadro efetivo, requisitados ou cedidos de outros órgãos, como também comissionados sem vínculo efetivo, mas também os trabalhadores auxiliares que contribuem para a estrutura da força do trabalho, como os terceirizados, estagiários, os juízes leigos, conciliadores e colaboradores voluntários. A estrutura do campo judiciário é composta por um total de 450.175 pessoas e a sua distribuição aponta para uma maior concentração desta equipe na justiça estadual, que contém 12.472 magistrados, seguida pela justiça do trabalho com 3.599 magistrados, e a justiça federal com 1.917 magistrados. Neste planejamento de pessoal cabe contabilizar 174.487 servidores lotados na justiça estadual; outros 40.338, da justiça do trabalho e 28.410, na justiça federal. A força de trabalho dos auxiliares é formada por 159.896 colaboradores com a seguinte proporcionalidade 46,2\% correspondem aos terceirizados; os estagiários, 40,4\%; conciliadores, 7,4\%; voluntários, 2,5\%; juízes leigos, 1,8\%; $1,7 \%$ trabalhadores de serventias privatizados, todos atuando em contribuição aos indicadores de gestão de forma diligente, no que diz respeito ao planejamento estratégico traçado para atender os múltiplos segmentos de justiça.

É cabível considerar que os processos em fase de execução contribuem, em grande parte, para a manutenção do perfil de morosidade, pois o Poder Judiciário, com um acervo de 79 milhões de processos pendentes possui, retém na fase de execução, 54,2\% deste volume, isto é, não há satisfatividade da prestação jurisdicional. Esta situação promove impactos não só na taxa de congestionamento, como também na qualidade da tutela judicial, uma vez que descumpre 
preceito fundamental contido na Constituição. Este acervo na fase de execução pode ser traduzido como o esgotamento dos meios previstos em lei sem que houvesse a localização de patrimônio capaz de satisfazer o crédito, o que ainda retém o elevado número de feitos, como apontado. Enquanto isto, o tempo de tramitação do processo continuará elevado, já que é contabilizado todo o lapso temporal existente entre a distribuição da ação e a baixa definitiva.

Numa universalidade de 78,7 milhões de processos em tramitação, excetuados 17,9\% de processos suspensos, sobrestados ou em arquivo provisório, apenas apresentaram redução no volume de casos pendentes, como início de postura de efetividade da prestação jurisdicional pelos desempenhos exibidos a justiça trabalhista e os juizados especiais federais, que apresentaram redução do estoque diante do volume de casos novos. O volume médio de ações, no ano de 2018, evidencia que a cada grupo de 100.000 habitantes, 11.796 buscaram o aceso à justiça, importando assinalar que a estrutura judiciária está em plena modernização para acompanhar as demandas sociojurídicas, recorrendo à utilização de processos judiciais eletrônicos, mas que ainda vivencia entraves à gestão estratégica do campo judiciário e, consequentemente, influenciando o resultado final de razoável duração do processo.

\section{REFERÊNCIAS}

BRASILIA. Conselho Nacional de Justiça. Recomendação 27. Disponível em: http://www.cnj.jus.br/atos-normativos?documento=873. Acesso em 03.Abr.2016.

BRASILIA. Conselho Nacional de Justiça. Resolução n. 185. Disponível em: http://www.cnj.jus.br/images/atos_normativos/resolucao/resolucao_185_18122013_0701201416 1739.pdf. Acesso em 03.Abr.2016.

BRASILIA. Conselho Nacional de Justiça. Justiça em Números 2019. Brasília: CNJ, 2019.

Disponível em https://www.cnj.jus.br/wp-

content/uploads/conteudo/arquivo/2019/08/justica_em_numeros20190919.pdf. Acesso em 02.abr.2020.

BUENO, Casio Scarpinella. Novo Código de Processo Civil anotado. São Paulo: Saraiva, 2015.

CAPPELlETti, Mauro. GARTH, Bryant. Acesso à Justiça. Tradução de Ellen Gracie Northfleet. Porto Alegre, Fabris, 2002. 
CUNHA, José Sebastião Fagundes. (coordenador geral). BACHENEK, Antonio Cesar. CAMBI, Eduardo. Código de Processo Civil comentado. São Paulo: Revista dos Tribunais, 2016.

GRECO, Leonardo. Instituições de processo civil. Introdução do Direito Processual Civil. Volume I. 5a edição revista, atualizada e ampliada. Rio de Janeiro: Forense, 2015.

MEDINA, JOSÉ Miguel Garcia. Direito processual civil moderno. São Paulo: Revista dos Tribunais, 2015.

PINHO, Humberto Dalla Bernardina de. Direito Processual civil contemporâneo. Volume I: teoria geral do processo. $6^{\text {a }}$ edição. São Paulo: Saraiva, 2015.

THEODORO JUNIOR, Humberto. Curso de direito processo civil. Teoria geral do direito processual civil, processo de conhecimento e procedimento comum. Vol. I. 56 $6^{\mathrm{a}}$. Ed. rev., atual. e ampl. Rio de Janeiro: Forense, 2015.

WAMBIER, Teresa Arruda (et alli). Breves comentários ao novo código de processo civil: artigo por artigo. São Paulo: Revista dos Tribunais, 2015.

WAMBIER, Luiz Rodrigues. TALAMINI, Eduardo. Curso Avançado de Processo Civil. Vol.

1. Teoria geral do processo e processo de conhecimento. $15^{a}$ edição, revista e atualizada. São Paulo: Revista dos Tribunais, 2015. 